УДК 372.8

\title{
ТЕНДЕНЦИИ ПРИОБЩЕНИЯ УЧАЩИХСЯ К РУССКОЙ НАРОДНОЙ КУЛЬТУРЕ
}

Чалых Анна Александровна студент Научный руководитель: Катханова Юлия Фёдоровна, д.П.Н., профессор ФГБОУ ВО «Московский педагогический государственный университет» Института изящных искусств

Аннотация. В статье рассмотрена важность приобщения учащихся к русской культуре, к народному искусству, а также к его наследию в процессе обучения изобразительному искусству. Раскрывая отдельные формы приобщения, учитель формирует у детей патриотическое отношение и любовь к своей стране, понимание того, что это и есть часть культуры, которая представляет связь народа, населяющих Россию. Без знаний своих корней, своих традиций нельзя сформировать толерантное сознание у человека, воспитать личность с ценностными ориентирами, являющимися главными факторами стабильного и социального равновесия в стране. Знание истоков народной культуры формирует у человека любовь к своим корням, а изобразительные методы передачи этой культуры дают возможность адекватно воспринимать окружающее пространство. К тенденции приобщения учащихся к художественно-творческому наследию мастеров мы относим визуализацию учебного материала средствами компьютерных технологий. Именно они содействуют лучшему восприятию, представлению и пониманию характера декоративно-прикладного искусства России, приобщая детей к культуре многих поколений в историческом периоде, сравнивая с современным миром материальной культуры.

Ключевые слова: приобщение, русская культура, приобщение к русской культуре, русский пейзаж, визуально-графический подход

\section{TRENDS OF STUDENTS'ACCOMPLISHMENT TO RUSSIAN FOLK CULTURE}


Abstract: The article examines the importance of familiarizing students with Russian culture, folk art, as well as its heritage in the process of teaching fine arts. Revealing individual forms of familiarization, the teacher forms in children a patriotic attitude and love for their country, an understanding that this is a part of culture, which represents the connection of the people inhabiting Russia. Without knowledge of their roots, their traditions, it is impossible to form a tolerant consciousness in a person, to educate a person with value orientations, which are the main factors of stable and social balance in the country. Knowledge of the origins of folk culture forms a person's love for their roots, and the pictorial methods of transferring this culture make it possible to adequately perceive the surrounding space. We attribute the visualization of educational material by means of computer technologies to the tendency to familiarize students with the artistic and creative heritage of masters. It is they who contribute to a better perception, presentation and understanding of the nature of decorative and applied art in Russia, introducing children to the culture of many generations in the historical period, comparing it with the modern world of material culture.

Key words: introduction, Russian culture, introduction to Russian culture, Russian landscape, visual-graphic approach

В художественной культуре существует тесная связь с изобразительным искусством. Картина, как отражение культуры - это взаимосвязь событий, передающихся из поколения к поколению. Это наследие, которое сохраняет многие ценности культуры, создаваемые в разные эпохи, в разные цивилизации. Национально-культурная идентичность для личности, включая художественное образование дает возможность визуально понять и принять ценности и характер русской культуры, часто являющейся опорой в сложных жизненных ситуациях, источником вдохновения в творчестве, а также важной частью духовного мира [1]. Отсюда учителю необходимо донести до сознания детей, что они являются носителями русской народной культуры, воспитать детей в духе национальных традиций.

В отсутствие каких бы то ни было общегосударственных идеологических установок, считается необходимым сначала дать специальную аргументацию положения о том, что приобщение детей к народной культуре является средством формирования у них патриотических чувств и развития духовности. Для этого необходимо специально остановиться на раскрытии таких понятий, как «национализм», «интернационализм» и «патриотизм». Патриотизм - это чувство любви к 
Родине. Понятие «Родина» включает в себя все условия жизни: территорию, климат, природу, организацию общественной жизни, особенности языка и быта, однако к ним не сводится. Историческая, пространственная, расовая связь людей ведет к формированию их духовного подобия. Сходство в духовной жизни способствует общению и взаимодействию, что в свою очередь порождает творческие усилия и достижения, придающие особое своеобразие народной культуре [2].

В своей истории многие народы осуществляют духовно-творческие свершения, переживающие века (древнегреческое искусство, римское право, германская музыка и т. д.). Каждый народ привносит в культуру свое, и каждое достижение народа является общим для всего человечества. Вот почему национальный гений и его творчество оказываются предметом особой патриотической гордости и любви [3]. В его творчестве находит сосредоточение и воплощение жизнь народного духа. Гений творит от себя, но в то же время за весь свой народ.

Россия - родина для многих. Но для того, чтобы считать себя ее сыном или дочерью, необходимо ощутить духовную жизнь своего народа и творчески утвердить себя в ней, принять русский язык, историю и культуру страны, как свои собственные. Однако национальная гордость не должна вырождаться в тупое самомнение и самодовольство. Настоящий патриот учится на исторических ошибках своего народа, на недостатках его характера и культуры [4].

Главное задание практической реализации системы патриотического воспитания заключается в том, что маленьким гражданам нужно привить:

- любовь к своему городу, улице, на которой живет школьник;

- чувство особой гордости за историю своей страны;

- уважение к культурному багажу предыдущих поколений;

- толерантность к разным чертам национального характера;

- самоуважение, которое является неотъемлемой частью самосознания гражданина;

- уважительное отношение к представителям других народов, а также своим сверстникам, родным и окружающим людям.

Патриотическое воспитание также включает работу с родителями (совместная подготовка тематических утренников или проектов, выставок, поделок) и работниками местных культурных центров (например, подключение сотрудников местного музея для проведения экскурсии) [5]. 
Необходимо обратиться к истокам русской народной культуры, русскому пейзажу и в первую очередь к фольклору.

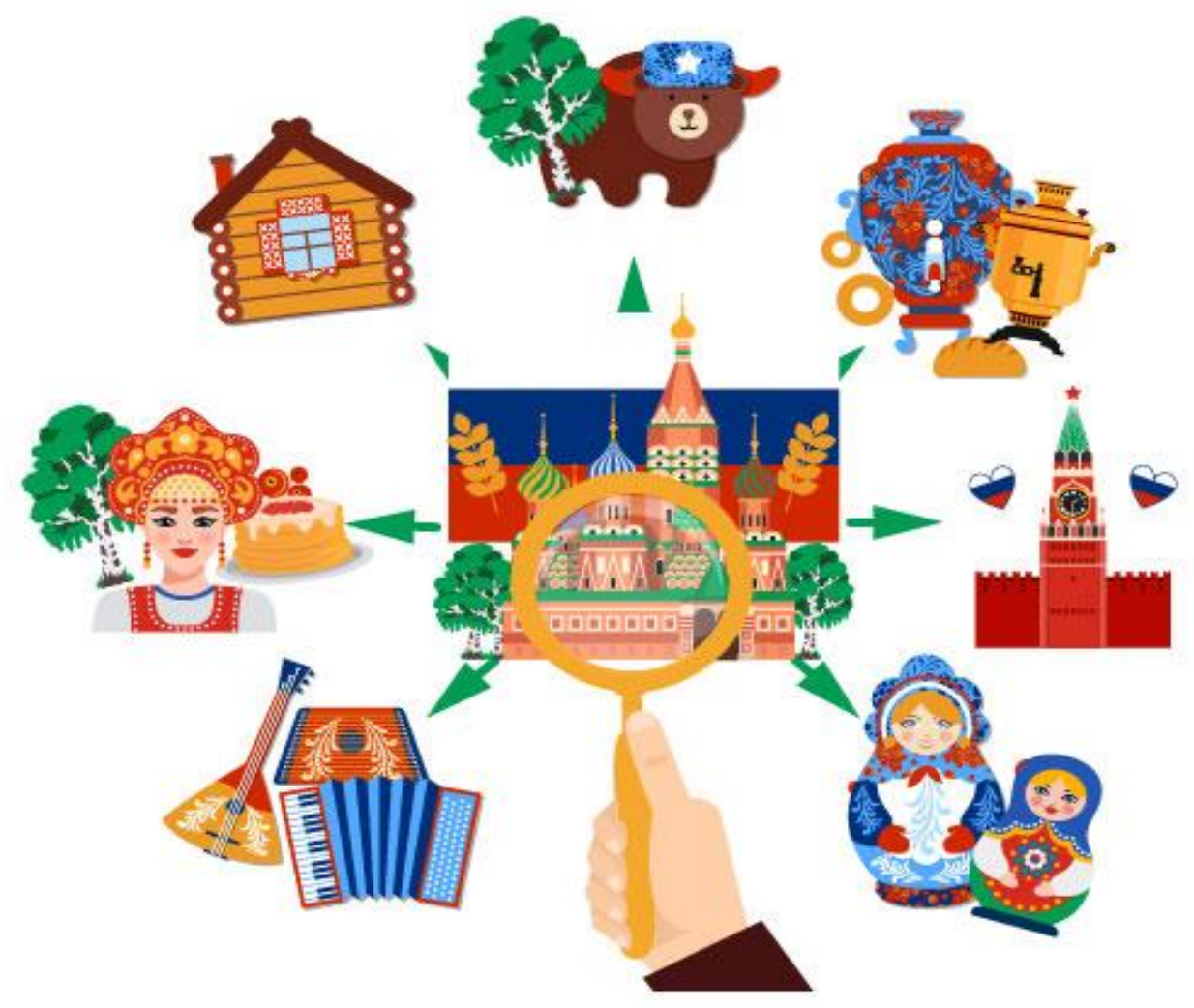

\section{Рис. 1. Символика и элементы русской культуры в компьютерной графике}

Способ приобщения может быть изложен современными методами. Обычно это актуальная тема сегодня потому, что в настоящее время вся информация приходит через персональный компьютер или мобильное устройство, мобильный телефон. Компьютерная графика понятна для восприятия современного школьника (рис. 1). Такая подача материала будет интересна как для ребенка, так и для более взрослого школьника.

Формат компьютерной игры даст заинтересованность и поможет глубже изучить истоки культуры. Обладая большим заделом информационнометодического материала, учитель при этом освобождается от рутинной работы. Быстрый доступ к различным образовательным материалам, связанным с любой темой учебного занятия, дает ему возможность сосредоточить свое внимание на решении других задач обучения, например, используя личностно-ориентированный подход к обучающимся, диалог, 
трансформируя информацию в знание и понимание. Причем, школьник, заинтересованный в знании культуры русского народа, сможет обмениваться полученной информацией со сверстниками, что дает возможность большему количеству детей узнать новое для себя. Нельзя не согласиться с Б.М. Неменским, что ребенка необходимо «...привязать всеми его чувствами, эмоциями к древу культуры его народа» [6].

Восприятие и приобщение детей к русской культуре на уроках изобразительного искусства с помощью визуальной подачи материала, помогает погрузиться в процесс обучения, развивает интерес к изучаемому учебному материалу, формирует патриотическое отношение к русской культуре, создает осознанный интерес к Родине, помогая развивать художественные навыки [7].

Изучение культуры русского народа в процессе обучения изобразительному искусству помогает расширить диапазон знаний по дисциплине, пополнить арсенал средств изобразительной деятельности, получить больше знаний из области изобразительного искусства, где школьники узнают больше ресурсов для работы в изобразительном искусстве. Использование при этом наглядных средств представления учебной информации способствует формированию у обучающихся умений обобщать, сравнивать, анализировать, систематизировать учебный материал. Наконец, знание и использование в образовательной среде материалов по культуре русского народа способствует эстетическому освоению действительности, а также творческому развитию личности и раскрытия еe творческого потенциала.

\section{Список литературы}

1. Князева О.Л. «Приобщение детей к истокам русской народной культуры» [Электронный ресурс] / О.Л. Князева. - URL: http://dou17. unosmirnih.ru/files/obr_prog/obr_pr_knyzeva.pdf.

2. Катханова Ю.Ф. Культура русского народа (DVD) http://teachpro.ru/course2d.aspx?idc=20199. Руководитель проекта и автор.2011.

3. Катханова Ю.Ф. Творческие способности и их развитие в графической деятельности // монография - Чебоксары: ИД «Среда», 2018. $140 \mathrm{c}$.

4. Кашекова И.Э. Специфика приобщения детей к ценностям народной культуры по программе «Мир художественных образов» [Электронный журнал] // Педагогика искусства: сетевой электронный научный журнал. - 
2016. - № 4. - URL:http://www.art-education.ru/electronicjournal/specifikapriobshcheniya-detey-k-cennostyam-narodnoy-kultury-po-programme-mir [дата обращения 21 ноября 2021].

5. Маханева М.Д. Нравственно-патриотическое воспитание детей старшего дошкольного возраста: Пособие для реализации Государственной программы «Патриотическое воспитание граждан Российской Федерации на 2001-2005 годы». - М.: АРКТИ, 2005. - 70 с.

6. Неменский Б.М. Мудрость красоты. - М.,1981. - 142 с.

7. Печко Л.П. Развитие культурно-эстетического сознания личности в процессе образования (к обоснованию концептуального подхода) [Электронный журнал] // Педагогика искусства: сетевой электронный научный журнал. - 2013. - №3. - URL: http://www.arteducation.ru/electronicjournal/razvitie-kulturno-esteticheskogo-soznaniya-lichnosti-vprocesseobrazovaniya-k [дата обращения 08 сентября 2021]. 